REUEVTED

\title{
Road Transportable Analytical Laboratory (RTAL) System
}

\section{Quarterly Report \\ May - July 1995}

August 1995

Work Performed Under Contract No.: DE-AC21-92MC29109

U.S. Department of Energy

Office of Environmental Management

Office of Technology Development

Washington, DC
For

U.S. Department of Energy

Office of Fossil Energy

Morgantown Energy Technology Center

Morgantown, West Virginia

By

Engineering Computer Optecnomics, Inc. (ECO) Annapolis, Maryland 



\section{DISCLAIMER}

This report was prepared as an account of work sponsored by an agency of the United States Government. Neither the United States Government nor any agency thereof, nor any of their employees, makes any warranty, express or implied, or assumes any legal liability or responsibility for the accuracy, completeness, or usefulness of any information, apparatus, product, or process disclosed, or represents that its use would not infringe privately owned rights. Reference herein to any specific commercial product, process, or service by trade name, trademark, manufacturer, or otherwise does not necessarily constitute or imply its endorsement, recommendation, or favoring by the United States Government or any agency thereof. The views and opinions of authors expressed herein do not necessarily state or reflect those of the United States Government or any agency thereof.

This report has been reproduced directly from the best available copy.

Available to DOE and DOE contractors from the Office of Scientific and Technical Information, 175 Oak Ridge Turnpike, Oak Ridge, TN 37831; prices available at (615) 576-8401.

Available to the public from the National Technical Information Service, U.S. Department of Commerce, 5285 Port Royal Road, Springfield, VA 22161; phone orders accepted at (703) 487-4650. 


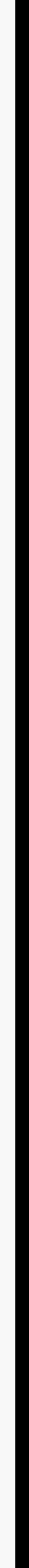


旁

资

క్․․

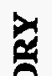

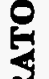

ํㅛㅇ

3

3

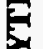



석

$\$$

舫

药

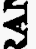

రి

हิ 



\title{
Road Transportable Analytical Laboratory (RTAL) System
}

\author{
Quarterly Report
}

May - July 1995

Work Performed Under Contract No.: DE-AC21-92MC29109

U.S. Department of Energy Office of Environmental Management Office of Technology Development 1000 Independence Avenue Washington, DC 20585
For

U.S. Department of Energy Office of Fossil Energy

Morgantown Energy Technology Center P.O. Box 880

Morgantown, West Virginia 26507-0880

By

Engineering Computer Optecnomics, Inc. (ECO)

1356 Cape St. Claire Center

Annapolis, Maryland 21401-5216 
. 


\section{Page}

Contract objective

TABLE OF CONTENTS

Introduction

Approach

Progress During Quarter

Plans for Next Quarter

overall Status Assessment 

The goal of the Road Transportable Analytical Laboratory (RTAL) Project is the development and demonstration of a system to meet the unique needs of the DOE for rapid, accurate analysis of a wide variety of hazardous and radioactive contaminants in soil, groundwater, and surface waters. This laboratory system has been designed to provide the field and laboratory analytical equipment necessary to detect and quantify radionuclides, organics, heavy metals and other inorganics. The laboratory system consists of a set of individual laboratory modules deployable independently or as an interconnected group to meet each DOE site's specific needs.

After evaluating the needs of the DOE field activities and investigating alternative system designs, the modules included in the RTAL are:

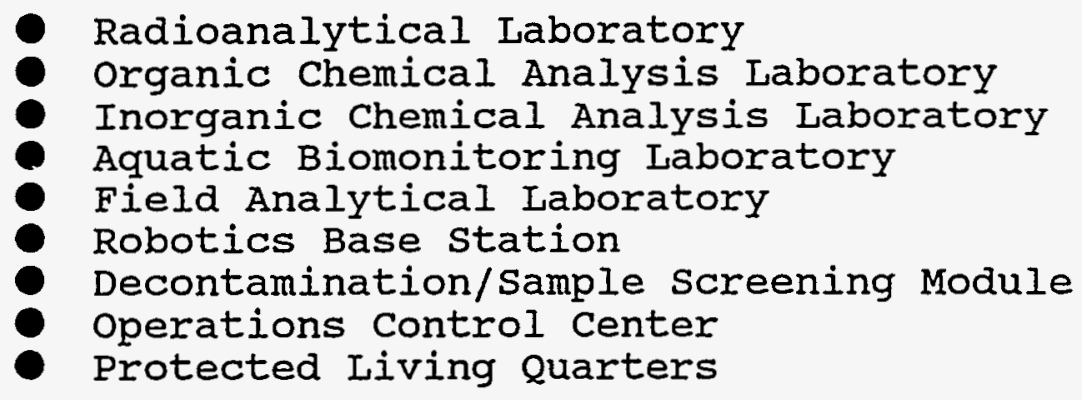

Each module provides full protection for operators and equipment against radioactive particulates and conventional environmental contaminants. This is especially important in areas where radioactive particulates from environmental matrices, e.g. soils, are aerosolized by wind or volatile chemicals are present. These contaminants can adversely affect sensitive chemical and radiochemical analyses as well as potentially being harmful to personnel.

The goal of the integrated laboratory system is a sample throughput of 20 samples per day, providing a full range of analyses on each sample within 16 hours (after sample preparation) with high accuracy and high quality assurance. The RTAL will provide the DOE with very significant savings in terms of both cost and time. This will accelerate and improve the efficiency of clean-up and remediation operations throughout the DOE complex. At the same time, the system will provide full protection for operating personnel and sensitive analytical equipment against the environmental extremes and hazards encountered at DOE sites. 



\section{INTRODUCTION}

U.S. Department of Energy (DOE) facilities around the country have, over the years, become contaminated with radionuclides and a range of organic and inorganic wastes. The major types of contamination found at the various sites have been summarized in the "Environmental Restoration and Management Five Year Plan" and, except for radionuclides (at most locations) and high explosives (at a few locations), are representative of the types of wastes found at many industrial facilities.

The DOE faces additional unique challenges in cleaning up this contamination. Many of the DOE sites encompass large land areas and were originally sited in relatively unpopulated regions of the country to minimize risk to surrounding populations. In addition, many times wastes were stored underground at the sites in 55-galion drums, wood boxes or other containers until final disposal methods could be determined. Over the years, these containers have deteriorated, releasing contaminants into the surrounding environment. This contamination has spread, in some cases polluting extensive areas.

Remediation of these sites requires extensive sampling to determine the extent of the contamination, to monitor cleanup and remediation progress, and for post-closure monitoring of facilities. The U.S. Environmental Protection Agency (EPA) has found that shipping samples to a central laboratory for analysis is a slow and expensive process. The EPA is emphasizing the use of field instrumentation and transportable laboratories to provide critical analytical data (which form the basis for remediation decisions) faster and at lower cost. The use of field systems can cut several weeks to months off the turnaround time for analytical information.

The DOE's problems in getting samples analyzed is further compounded by the almost universal presence of radionuclides in the samples. The DOE's samples require wipe tests for surface contamination before shipment and after receipt, specialized transportation containers and procedures (depending on the level of radioactivity present in the sample), and a substantial amount of additional paperwork. It can be very difficult and timeconsuming to ship samples off-site from DOE facilities because of requirements established to ensure against inadvertent release of radioactive materials. The occasional improper shipment of radioactive materials from DOE facilities has also led to periodic curtailment of all shipments to ensure that proper shipping procedures are followed. Such curtailments can cause havoc to projects where accurate sample analytical data is critical to decision-making and also because environmental samples degrade over time. 

Thus, the DOE would benefit greatly if it had reliable road transportable, fully independent laboratory systems that could perform on-site the full range of analyses required. Such systems could accelerate clean-up and remediation efforts by providing critical analytical data more rapidly, and save money by eliminating handling, transportation and manpower costs associated with sample shipments.

The current effort addresses the unique requirements of the DOE for a Road Transportable Analytical Laboratory (RTAL) system capable of analyzing for a wide variety of hazardous and radioactive contaminants in soil, groundwater, and surface waters. This effort is based on the earlier laboratories and operations control centers developed by Engineering Computer optecnomics (ECO), Inc. for the U.S. Environmental Protection Agency, and the U.S. Departments of Defense and State. These include counter-terrorist systems for use in areas contaminated with chemical or biological warfare agents. The advances achieved in the development of these earlier systems have been incorporated into the development of the RTAL.

The RTAL has been designed to provide for the efficient and effective operation of the field and laboratory analytical equipment necessary to detect and quantify radionuclides, organics, heavy metals and other inorganics. The integrated RTAL system will be able to provide a full range of accurate analyses on-site. At the same time, the RTAL system will provide full protection for the operating personnel and the sensitive analytical equipment against the environmental extremes and the hazards encountered at DOE sites.

\section{APPROACH}

The development of the Road Transportable Analytical Laboratory system is being conducted in two phases. Phase I, encompassing work at Maturity Level 4, Major Sub-systems, was for the development and optimization of the RTAL system design to most effectively meet the needs of the DOE. This phase incorporated development of detailed performance requirements (based on documented data and meetings with potential DOE users of the RTAL system), development and evaluation of alternative system configurations, and optimization of the final design. The work required under Phase I was completed on schedule and within budget.

Phase II of this project represents a transition to Maturity Level 5, Full-Scale Demonstration. A full-scale partial prototype of the RTAL system is being constructed. This partial prototype consists of the following three modules: 


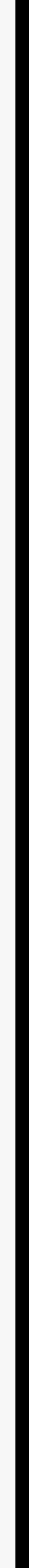




\section{- Radioanalytical Laboratory \\ - Organic Chemical Analysis Laboratory \\ - Operations Control Center}

The operations control center will be capable of accepting data from robotic site contaminant mapping equipment. In addition, the DOE and the U.S. Army have agreed in principle to augment the demonstration of the prototype RTAL with the following two Superfund TERMM ${ }^{\mathrm{TM}}$ laboratory modules, also designed and constructed by ECO, to be loaned by the Army:

\section{- Inorganic Chemical Analysis Laboratory - Aquatic Biomonitoring Laboratory}

This five-module prototype system will be tested at an appropriate DOE site to demonstrate the performance of the system and to quantify the cost and time savings it provides.

Upon completion of Phase II, ECO, Inc. will enter into commercial production of the Road Transportable Analytical Laboratory system, providing full warranties and guarantees for the product. The RTAL system will be integrated into ECO's existing line of TERMM ${ }^{\mathrm{TM}}$ and superfund TERMM ${ }^{\mathrm{TM}}$ modular transportable analytical laboratory and operational control systems.

\section{PROGRESS DURING QUARTER}

This report documents the progress achieved on the development of the RTAL system during the fifth quarterly period of the Phase II development, from May 1, 1995 through July 31, 1995. The Phase II effort under this contract is divided into five tasks:

$$
\begin{aligned}
& \text { Task } 1 \text { - NEPA Documentation } \\
& \text { Task } 2 \text { - Drawings } \\
& \text { Task } 3 \text { - Prototype System Construction } \\
& \text { Task } 4 \text { - On-Site Prototype Demonstration } \\
& \text { Task } 5 \text { - Final Report }
\end{aligned}
$$

Task 1 was completed earlier, resulting in the granting of a Categorical Exclusion. Task 2, Drawings, was also completed during prior work quarters. During this quarter, work continued on Tasks 3 and 4 . Task 5 has not yet been initiated in accordance with tre project schedule. The progress achieved on Tasks 3 and 4 is discussed below.

Installation of the radioanalytical instrumentation in the Radioanalytical Laboratory was completed during June and the Factory Acceptance Test took place on July 6 . The 

radioanalytical instrumentation in this laboratory includes two Germanium Detectors (weighing 5,000 Ib. each), 24 Alpha Spectrometers, a Liquid Scintillation Counter, and a Gross Alpha/Beta Counter.

The delivery of this module to Fernald Environmental Management Project (FEMP) was originally scheduled for July 14. However, in a letter dated June 12, Mr. D. Herman of FEMP said delivery would have to be delayed due to the late receipt of funds covering FEMP's involvement in the RTAL demonstration. The FEMP funding for the demonstration of the prototype RTAL was forwarded by METC in June. It was decided that it would be more efficient if FEMP prepared more fully for the receipt of the RTAL modules and therefore, delivery of the Radioanalytical Laboratory was delayed until August 24. A letter documenting computer hardware and software included in this laboratory was provided to Mr. Heath, as requested. ECO will continue to coordinate delivery of the RTAL modules with FEMP.

All the analytical instrumentation for the organic Chemical Analysis Laboratory was received and installation was completed during July. Analytical instrumentation for this laboratory includes a Gas Chromatograph (GC)/Mass spectrometer (MS), purge and Trap GC/MS, GC with Flame Ionization Detector, automated Iiquid/Iiquid Extractor, automated Solid/Liquid Extractor, Size Exclusion Chromatograph, and Toxicity Characteristic Leachate Procedure (TCLP) Apparatus. Performance Testing of the analytical equipment is scheduled for August 1.

The operations Control Center is also essentially complete. This module's computers and wireless Local Area Network (LAN) hardware have been received. An internal demonstration of the wireless LAN software was successfully completed on June 6 and an inter-module demonstration was successfully completed on July 19 . During this test, an operator in the operations control center demonstrated monitoring and control of computers in the organic Chemical Analysis Laboratory. This system will allow oversight and control of all the analytical instrumentation in the Radioanalytical and organic Chemical Analysis Laboratories from the operations control center. The integrated control of the analytical equipment contributes to the lower manning requirements and efficiency of the RTAL.

The Test Plan and analytical procedures for the demonstration of the prototype RTAL system were delivered to METC (J. Malhotra) and FEMP (R. Heath) during May. The analytical procedures are based on FEMP or other DOE site procedures, modified as necessary for efficient operation within the prototype RTAL.

Mr. R. Heath and Mr. K. Payne are working on the FERMCO/FEMP paperwork necessary for the RTAL demonstration. Due to the 


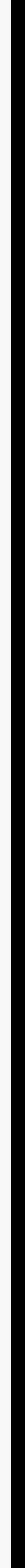


numerous documents that must be prepared and the required reviews they must undergo, Mr. Heath estimated that the demonstration could be started in November or December (it was originally scheduled for September-October). ECO personnel will continue to work closely with FEMP to expedite the preparation and review of the necessary documents.

The placement of the labs for the demonstration has been the subject of considerable discussion. The current plan is to place the three prototype RTAL modules adjacent to the oU-1 waste pits. This area is a good source of samples and has good utility support.

The U.S. Army Biomedical R\&D Laboratory (USABRDL) is providing two laboratories to support the demonstration of the prototype RTAL. The USABRDL Chemical Analysis Laboratory will provide an Inductively Coupled Plasma (ICP) Spectrometer for analysis of metals in environmental samples. The Aquatic Biomonityoring Laboratory will be used to demonstrate Integrated Environmental Assessment techniques using aquatic organisms for on-site evaluation of acute toxicity, carcinogenicity, genetic toxicity, and neurotoxicity of groundwater, discharge waters, and other environmental media. USABRDL has specified that their laboratories not be exposed to radioactive wastes. Accordingly, the USABRDL labs will be placed near the stormwater Retention Basin (SWRB) and surrogate samples will be used for heavy metals analyses. The SWRB area is uncontaminated, has a continuous supply of potential test water (necessary for demonstration of the Integrated Biological Assessment), and good utility support.

USABRDL may bring their operations Control Center in addition to their Chemical Analysis Laboratory and Aquatic Biomonitoring. Laboratory. They requested inclusion of this additional module since they use it to control and manage data from the other two labs. Mr. Heath was contacted concerning this request and indicated this should not be a problem.

\section{PLANS FOR NEXT QUARTER}

The plans for the upcoming quarter, from August through October 1995, call for the completion of Task 3, Prototype system Construction, and a strong focus on Task 4, On-site Prototype Demonstration. All three prototype laboratories will be delivered to FEMP by September. Site-specific operator training will probably be provided by FEMP during october. Assuming siterequired planning documents have completed review, operations within the prototype RTAL labs can commence in November. 



\section{OVERALL STATUS ASSESSMENT}

The Phase IIb effort for the development of the prototype RTAL system is on schedule and within budget. All contractual requirements to date have been met. The delay in FEMP's receipt of funding from the DOE to cover its expenses in connection with the demonstration has been a concern. However, FEMP personnel are working hard to complete preparations for the demonstration, e.g. site-required plans and other documents, sample acquisition and utilities. ECO will continue to work closely with FEMP to maintain the progress on this important project. 


,

